\title{
Maternal and foetal outcomes among pregnant women hospitalised due to interpersonal violence: A population based study in Western Australia, 2002-2008
}

\author{
Lynn B Meuleners ${ }^{1 *}$, Andy H Lee ${ }^{2}$, Patti A Janssen ${ }^{3}$ and Michelle L Fraser ${ }^{1}$
}

\begin{abstract}
Background: Interpersonal violence is responsible for more ill-health and premature death in women under the age of 45 than other preventable health conditions, but findings concerning the effects of violence during pregnancy on both maternal and foetal health have been inconsistent.

Methods: A retrospective population-based cohort study was undertaken using linked data from the Hospital Morbidity Data Collection and the Western Australian Midwives' Notification System from 2002 to 2008. The aim was to determine the association between exposure to interpersonal violence during pregnancy and adverse maternal and foetal health outcomes at the population level.

Results: A total of 468 pregnant women were hospitalised for an incident of interpersonal violence during the study period, and 3,744 randomly selected pregnant women were included as the comparison group. The majority of violent events were perpetrated by the pregnant women's partner or spouse. Pregnant Indigenous women were over-represented accounting for $67 \%$ of all hospitalisations due to violence and their risk of experiencing adverse maternal outcomes was significantly increased compared to non-Indigenous women (adjusted odds ratio 1.53, 95\% $\mathrm{Cl} 1.21$ to $1.95, \mathrm{p}=0.01$ ). Pregnant women hospitalised for an incident of interpersonal violence sustained almost double the risk for adverse maternal complications than the non-exposed group (95\% Cl 1.34 to 2.18, $\mathrm{p}<0.001$ ). The overall risk for adverse foetal complications for pregnant women exposed to violence was increased two-fold ( $95 \%$ Cl 1.50 to $2.76, \mathrm{p}<0.001$ ).

Conclusions: The risk of adverse health outcomes for both the mother and the baby increases if a pregnant woman is hospitalised for an incident of interpersonal violence during pregnancy.
\end{abstract}

\section{Background}

Interpersonal violence is responsible for more ill-health and premature death in women under the age of 45 years than any other preventable health conditions such as hypertension, obesity and diabetes [1]. When interpersonal violence is experienced during pregnancy, it not only affects the health and well-being of the mother but is also associated with adverse health outcomes for the foetus [2]. This has significant ramifications because

\footnotetext{
* Correspondence: L.Meuleners@curtin.edu.au

'Curtin-Monash Accident Research Centre (C-MARC), School of Public Health, Curtin University, GPO Box U1987, Perth, Western Australia 6845, Australia Full list of author information is available at the end of the article
}

negative birth outcomes represent a significant cost to society. For example, low birth weight and pre-term infants contribute disproportionately to neonatal morbidity and health care costs, as well as leading to a multitude of short and long term health problems [3].

The term 'interpersonal violence' refers to "the intentional use of physical force, or power, threatened or actual, against oneself, another person, or against a group or community, that either results in, or has a likelihood of resulting in injury, death, psychological harm, mal-development or deprivation" [4]. This definition includes victimisation perpetrated against intimate partners, parents, siblings, children, other relatives, friends,

\section{C) Biomed Central}


acquaintances, colleagues and strangers [4-6]. Interpersonal violence during pregnancy may be perpetrated by current or previous intimate partners, family members, and strangers or may occur as a result of fighting. Previous research, however, has indicated that violence during pregnancy is more commonly perpetrated by an intimate partner [7-9].

The effects of violence during pregnancy on both maternal and foetal health have been extensively investigated in the literature. However, conflicting results have been reported, possibly due to limitations in sample sizes, study methodology and operational definitions $[10,11]$. Recent studies conducted in the USA used population-based data to examine the adverse effects of violence during pregnancy $[12,13]$. In Western Australia (WA), a population-based study reported a rising incidence of interpersonal violence hospitalisations particularly among women of child bearing age, highlighting this serious public health issue [14]. However, there has been minimal research specifically targeting this vulnerable group in Australia.

This population-based, retrospective cohort study utilised the Western Australian Data Linkage System to determine the association between exposure to interpersonal violence during pregnancy and adverse maternal and foetal health outcomes from 2002 to 2008.

\section{Methods}

\section{Study design}

A retrospective population-based cohort study was undertaken.

\section{Definition and databases}

The study used administrative data from the Western Australian Data Linkage System which represents one of only a small number of record linkage systems in the world. It records longitudinal data on the use of health services and vital events for the entire Western Australian population of over 2.2 million people. De-identified data were obtained through the linkage of the Hospital Morbidity Data Collection (HMDC) and the Western Australian Midwives' Notification System. The HMDC contains information concerning all inpatient discharge summary data from all public and private hospitals in Western Australia from 1970 onwards. The Western Australian Midwives' Notification System contains the mother's demographic information, details of the pregnancy, labour, delivery, gestational age of baby and birth records (both live and death records) from 1980 onwards.

Cases consisted of all women who were pregnant and admitted to a WA hospital between January 2002 and December 2008 due to involvement in an incident of interpersonal violence. A case was identified as a victim of interpersonal violence' if the principal diagnosis for at least one hospital separation during pregnancy was an 'injury', as designated by a diagnosis code between S00.0 and T98.3 (Chapter XIX, ICD-10-AM), and a primary external cause indicating that at least one injury in the case record was inflicted by another person, as designated by external cause codes between X85 and Y09 (ICD-10-AM) [15]. Pregnancy was defined by ICD 10AM codes 000-082, Z33, Z32.1, Z34-Z35, Z37. At least ten months of data before and after the hospital admission for violence were extracted from the hospital morbidity records. These records were then linked to the Western Australian Midwives' Notification System to identify maternal birth and foetal outcomes. The comparison group was randomly selected from women who had only been admitted to hospital for a pregnancyrelated event including the delivery episode and had no diagnosis of interpersonal violence for that event or prior to or after the pregnancy. A look back period of 10 months before and after the delivery date was chosen to ensure there was no mis-classification. These records were then linked to the Western Australian Midwives' Notification System to identify maternal birth and foetal outcomes for that group.

In this study, adverse maternal birth outcomes included threatened abortion $(<20$ weeks), placental abruption, placental praevia, preterm labour, premature rupture of the membranes, and postpartum haemorrhage. Adverse foetal birth outcomes included foetal distress, low birth weight (less than $2500 \mathrm{~g}$ ), infant death and foetal death.

The circumstance of the violence event was defined by the major injury grouping framework devised by the Center for Disease Control and Prevention. The external cause codes for injury inflicted by another was divided into four sub-groups designating the following methods of inflicting injury: 'by bodily force' (Y04 [ICD-10-AM]), 'by sharp or blunt object' (Y99, Y00 [ICD-10-AM]), 'by maltreatment or rape' (Y05, Y06.0-9, Y07.0-9 [ICD-10$\mathrm{AM}]$ ) and 'by other methods' (all other codes between X85 to Y09 (ICD-10-AM) [15]. Meanwhile, the relationship of the perpetrator to the victim was identified using the fifth digit classification of the external cause of injury codes.

This study was conducted in accordance to the guidelines of the Declaration of Helsinki. Ethical approval was obtained from both the Human Research Ethics Committee at Curtin University and the Data Linkage Branch of the Department of Health WA.

\section{Statistical analysis}

Descriptive statistics were used to summarise the demographic profile of the sample, including circumstances of the injury event and perpetrator-victim relationship. 
Chi-squared tests were undertaken to compare demographic characteristics and maternal and foetal outcomes between pregnant women hospitalised for violence and those not hospitalised for violence. Odds ratios and confidence intervals were calculated using multivariable logistic regression models after accounting for potential confounders namely age, maternal smoking and Indigenous status which can affect maternal and foetal outcomes [10-13]. Two separate logistic regression models were undertaken. For the first model, the outcome of interest was adverse maternal outcomes which included threatened abortion ( $<20$ weeks gestation), preterm labour $(<37$ weeks), pre-labour rupture of the membranes, postpartum haemorrhage $(\geq 500 \mathrm{ml})$, placental previa, placental abruption, and other causes of antepartum haemorrhage. For the second model, the outcome of interest was adverse foetal outcomes which included foetal distress, infant death, low birth weight and foetal death. All statistical analyses were performed in the SAS package version 9.1 [16].

\section{Results}

A total of 468 women were admitted to hospital after involvement in at least one incident of interpersonal violence while pregnant from 2002 to 2008. A comparison group of 3,744 pregnant women hospitalised for a pregnancy related event including delivery but who did not have a record for an incident of interpersonal violence throughout their pregnancy were randomly selected. The sample characteristics of both groups are presented in Table 1.

A large majority of pregnant women exposed to violence tended to be 25 years of age and under (61.6\%), Indigenous (66.5\%), multiparous (65.2\%), smoked during their pregnancy $(59.0 \%)$, and were not in a married or de-facto relationship (59.1\%). The most common type of violence was inflicted by bodily force ( $65.8 \%$ of cases), followed by rape $(15.4 \%)$, assault with a blunt/sharp object $(11.1 \%)$ and other types of assault (11.1\%). Of those cases where a code existed describing the relationship between the perpetrator and the victim (72.0\%), the majority of pregnant women were assaulted by either their spouse or partner $(69.5 \%)$, followed by a person where the relationship was not specified $(20.8 \%)$, or another family member (5.6\%) (not shown in the table).

Table 2 shows maternal and foetal outcomes by violence exposure status. Threatened abortions ( $<20$ weeks) occurred significantly more often among women in the non-exposed group than the exposed group. Other maternal complications occurred significantly more often among women exposed to violence than nonexposed women during their pregnancy.

The non-exposed group of women reported a significantly higher percentage of foetal distress compared to women who had been exposed to violence during their pregnancy. Adverse foetal outcomes such as low birth weight and foetal deaths, however, occurred significantly more often among women exposed to violence during their pregnancy, compared to the non-exposed group.

\section{Risk of adverse maternal outcomes}

As shown in Table 3, exposure to violence during pregnancy was associated with a 1.7 fold-increase in the risk of maternal complications (95\% CI 1.34 to 2.18 , p < $0.001)$. These complications included threatened abortions, preterm labour, antepartum haemorrhage (due to placenta praevia, placental abruption or other), prelabour rupture of membranes and postpartum haemorrhage. The increase in risk was evident after accounting for potential confounders. Indigenous women also had a 1.5-fold increased risk of experiencing maternal complications relative to non-Indigenous women (95\% CI 1.21 to $1.95, \mathrm{p}=0.01$ ).

\section{Risk of adverse foetal outcomes}

As shown in Table 4, the risk of adverse foetal outcomes, which included low birth weight, foetal distress, and foetal/infant death, among women who had been hospitalised due to violence during their pregnancy, was double that of women who had not been exposed to violence $(95 \%$ CI 1.50 to $2.76, \mathrm{p}<0.001)$. Similarly, Indigenous status was significantly associated with a 2 -fold increased risk for adverse foetal outcomes. Non-smoking by the pregnant women significantly reduced the risk of experiencing negative foetal outcomes by $37 \%$ (95\% CI 0.50 to 0.79 , $\mathrm{p}<0.001)$.

\section{Discussion}

The study has highlighted that pregnant women exposed to violence may sustain poor health outcomes for themselves and their baby. In this whole population study, pregnant women hospitalised for an incident of interpersonal violence were at almost double the risk of experiencing one or more adverse maternal complication than the non-exposed group. The findings provide further evidence of an association between antepartum hemorrhage and exposure to violence [17]. Violence is often directed towards the pregnant women's abdomen and the high prevalence of injury due to blunt force may explain these results [17] Consistent with previous research,[7-9] the majority of violent events were perpetrated by the pregnant women's partner or spouse. The overall risk of one or more adverse foetal complications among pregnant women exposed to violence was also increased 2-fold.

It is important to note the multifactorial relationship between violence and its impact on maternal and foetal outcomes during pregnancy.[9,12,13,18-27] Similar to 
Table 1 Demographic, clinical and lifestyle characteristics of pregnant women hospitalised for interpersonal violence and a comparison group: Western Australia, 2002-2008

\begin{tabular}{|c|c|c|c|c|c|}
\hline & $\begin{array}{l}\text { Pregnant women hospitalised for interpersonal } \\
\text { violence }(n=468)\end{array}$ & & $\begin{array}{l}\text { Pregnant women not hospitalised for interpersonal } \\
\text { violence }(n=3,744)\end{array}$ & & $\mathrm{P} * * * *$ \\
\hline & $n$ & $\%$ & $n$ & $\%$ & \\
\hline $\begin{array}{l}\text { Women's age } \\
\text { (years) }\end{array}$ & & & & & $<0.001$ \\
\hline$\leq 20$ & 140 & 30.0 & 419 & 11.2 & \\
\hline $21-25$ & 148 & 31.6 & 685 & 18.3 & \\
\hline $26-30$ & 98 & 20.9 & 1,153 & 30.8 & \\
\hline $31-35$ & 50 & 10.7 & 1,017 & 27.2 & \\
\hline$\geq 36$ & 32 & 6.8 & 470 & 12.6 & \\
\hline $\begin{array}{l}\text { Indigenous } \\
\text { status }\end{array}$ & & & & & $<0.001$ \\
\hline Yes & 311 & 66.5 & 193 & 5.2 & \\
\hline No & 157 & 33.5 & 3,551 & 94.8 & \\
\hline Parity* & & & & & $<0.001$ \\
\hline 0 & 88 & 18.8 & 1,637 & 43.7 & \\
\hline 1 & 75 & 16.0 & 963 & 25.7 & \\
\hline 2 & 82 & 17.5 & 558 & 14.9 & \\
\hline $3+$ & 223 & 47.7 & 586 & 15.7 & \\
\hline $\begin{array}{l}\text { Gestational age } \\
\text { (weeks) }\end{array}$ & & & & & $<0.001$ \\
\hline$\leq 27$ & 13 & 2.8 & 32 & 0.9 & \\
\hline $28-32$ & 18 & 3.9 & 44 & 1.2 & \\
\hline $33-36$ & 65 & 13.9 & 212 & 5.7 & \\
\hline$\geq 37$ & 372 & 79.5 & 3,456 & 92.3 & \\
\hline Marital status & & & & & $<0.001$ \\
\hline Yes** & 183 & 40.9 & 2,823 & 76.3 & \\
\hline $\mathrm{No}^{* * *}$ & 264 & 59.1 & 879 & 23.7 & \\
\hline $\begin{array}{l}\text { Maternal } \\
\text { smoking }\end{array}$ & & & & & $<0.001$ \\
\hline Yes & 276 & 59.0 & 691 & 18.5 & \\
\hline No & 192 & 41.0 & 3,053 & 81.5 & \\
\hline
\end{tabular}

* Parity is defined as the number of live-born children a woman has delivered; ** married or de facto relationship; ${ }^{* *}$ widowed, divorced or single; ${ }^{* * *} \mathrm{P}$ values from chi-squared tests

the literature, $[12,28-30]$ certain demographic characteristics were found to be associated with the risk of violence, such as younger age, marital status and parity. Population subgroups should be targeted for violence screening and counselling during pregnancy.

While mixed findings have been reported on the association between ethnicity and rates of interpersonal violence in the US and South America, [25,31,32] it is evident that significant differences exist between Indigenous and non-Indigenous pregnant women. Pregnant Indigenous women accounted for $67 \%$ of all hospitalisations due to violence despite representing approximately $4 \%$ of the WA population. This is consistent with previous research which identified that hospital admissions by Indigenous females due to violence were consistently higher than Indigenous males, non-Indigenous males and females [14]. High rates of established behavioural health factors such as being disadvantaged economically, broken family ties, smoking, alcohol and substance abuse increased the risk of experiencing interpersonal violence among Indigenous families, $[33,34]$ which may explain the higher occurrence of interpersonal violence related hospitalisations among our cohort of Indigenous women. In addition, the risk of experiencing adverse maternal and foetal outcomes for this group was significantly increased. These findings have important implications for the planning of health services and distribution of resources to effectively reduce the burden of interpersonal violence in the Indigenous community.

This study has addressed a number of shortcomings of past research. The use of the WA Data Linkage System assisted in reducing selection bias, minimised loss to follow up and enabled the assessment of the association between pregnant women exposed to violence and adverse maternal and foetal outcomes at the population level. It also had the advantage of detecting small 
Table 2 Maternal and foetal outcomes among pregnant women hospitalised for interpersonal violence and a comparison group: Western Australia, 2002-2008

\begin{tabular}{|c|c|c|c|c|c|}
\hline & $\begin{array}{l}\text { Pregnant women hospitalised for } \\
\text { interpersonal violence }(n=468)\end{array}$ & & $\begin{array}{l}\text { Pregnant women not hospitalised for } \\
\text { interpersonal violence }(n=3,744)\end{array}$ & & $\mathrm{P} * * *$ \\
\hline Outcomes & $n$ & $\%$ & $n$ & $\%$ & \\
\hline \multicolumn{6}{|l|}{ Maternal } \\
\hline $\begin{array}{l}\text { Threatened abortions } \\
\text { ( }<20 \text { weeks })\end{array}$ & 12 & 2.6 & 218 & 5.8 & $<0.001$ \\
\hline $\begin{array}{l}\text { Threatened preterm } \\
\text { labour (<37 weeks) }\end{array}$ & 42 & 9.0 & 96 & 2.6 & $<0.001$ \\
\hline $\mathrm{APH}^{*}$ - placenta praevia & 5 & 1.1 & 28 & 0.7 & 0.46 \\
\hline APH - placental abruption & 3 & 0.6 & 13 & 0.3 & 0.41 \\
\hline APH - other & 16 & 3.4 & 110 & 2.9 & 0.56 \\
\hline $\begin{array}{l}\text { Pre-labour rupture of } \\
\text { membranes }\end{array}$ & 43 & 9.2 & 210 & 5.6 & $<0.001$ \\
\hline $\mathrm{PPH}^{* *}(\geq 500 \mathrm{ml})$ & 68 & 14.5 & 356 & 9.5 & $<0.001$ \\
\hline \multicolumn{6}{|l|}{ Foetal } \\
\hline Foetal distress & 65 & 13.9 & 599 & 16.0 & $<0.001$ \\
\hline Low birth weight & 115 & 24.6 & 243 & 6.5 & $<0.001$ \\
\hline Foetal death & 5 & 1.1 & 6 & 0.2 & 0.02 \\
\hline Infant death & 1 & 0.2 & 26 & 0.7 & 0.35 \\
\hline
\end{tabular}

${ }^{*} \mathrm{APH}=$ Antepartum haemorrhage; ${ }^{*} \mathrm{PPH}=$ Postpartum haemorrhage; ${ }^{* * *} \mathrm{P}$ values from chi-squared tests

Table 3 Results of multivariable logistic regression for adverse maternal outcomes among pregnant women hospitalised due to interpersonal violence: Western Australia, 2002-2008

\begin{tabular}{|c|c|c|c|}
\hline & $\begin{array}{l}\text { Adverse maternal } \\
\text { outcomes }\end{array}$ & & \\
\hline & Adjusted odds ratio & $\mathbf{P}$ & $95 \% \mathrm{Cl}$ \\
\hline \multicolumn{4}{|c|}{ Exposed to violence } \\
\hline \multicolumn{4}{|l|}{$\mathrm{No}^{*}$} \\
\hline Yes & 1.70 & $<0.001$ & $\begin{array}{l}1.34- \\
2.18\end{array}$ \\
\hline \multicolumn{4}{|c|}{ Maternal smoking } \\
\hline \multicolumn{4}{|l|}{ Yes* } \\
\hline No & 0.92 & 0.27 & $\begin{array}{l}0.78- \\
1.07\end{array}$ \\
\hline \multicolumn{4}{|c|}{ Indigenous status } \\
\hline \multicolumn{4}{|l|}{$\mathrm{No}^{*}$} \\
\hline Yes & 1.53 & 0.01 & $\begin{array}{l}1.21- \\
1.95\end{array}$ \\
\hline \multicolumn{4}{|c|}{$\begin{array}{l}\text { Women's age } \\
\text { (years) }\end{array}$} \\
\hline \multicolumn{4}{|l|}{$\leq 20^{*}$} \\
\hline $21-25$ & 1.06 & 0.62 & $\begin{array}{l}0.85- \\
1.32\end{array}$ \\
\hline $26-30$ & 1.04 & 0.70 & $\begin{array}{l}0.84- \\
1.29\end{array}$ \\
\hline $31-35$ & 1.12 & 0.32 & $\begin{array}{l}0.90- \\
1.39\end{array}$ \\
\hline$\geq 36$ & 1.26 & 0.08 & $\begin{array}{l}0.98- \\
1.62\end{array}$ \\
\hline
\end{tabular}

\footnotetext{
* Reference group
}

differences by inclusion of a large number of cases. Another strength was the use of high quality, objective data which should be more accurate than information obtained via participant self-report measures $[35,36]$. Moreover, the results obtained from this populationbased study may be generalisable to the rest of Australia, because WA is considered to be representative of

Table 4 Results of multivariable logistic regression for adverse foetal outcomes among pregnant women hospitalised due to interpersonal violence: Western Australia, 2002-2008

\begin{tabular}{|c|c|c|c|}
\hline \multicolumn{4}{|c|}{ Adverse foetal outcomes } \\
\hline & Adjusted odds ratio & $P$ & $95 \% \mathrm{Cl}$ \\
\hline \multicolumn{4}{|c|}{ Exposed to violence } \\
\hline \multicolumn{4}{|l|}{$\mathrm{No}^{*}$} \\
\hline Yes & 2.03 & $<0.001$ & $1.50-2.76$ \\
\hline \multicolumn{4}{|c|}{ Maternal smoking } \\
\hline \multicolumn{4}{|l|}{ Yes* } \\
\hline No & 0.63 & $<0.001$ & $0.50-0.79$ \\
\hline \multicolumn{4}{|c|}{ Indigenous status } \\
\hline \multicolumn{4}{|l|}{$\mathrm{No}^{*}$} \\
\hline Yes & 2.04 & $<0.001$ & $1.50-2.77$ \\
\hline \multicolumn{4}{|c|}{ Women's age (years) } \\
\hline \multicolumn{4}{|l|}{$\leq 20^{*}$} \\
\hline $21-25$ & 1.02 & 0.89 & $0.74-1.41$ \\
\hline $26-30$ & 0.92 & 0.61 & $0.67-1.26$ \\
\hline $31-35$ & 1.25 & 0.17 & $0.91-1.73$ \\
\hline$\geq 36$ & 1.25 & 0.25 & $0.85-1.82$ \\
\hline
\end{tabular}

* Reference group 
the broader Australian population in terms of key sociodemographic and health economic indicators [37].

Several limitations should be taken into account. Firstly, our findings reflect only the severe cases of interpersonal violence, namely those which led to hospitalisation. Therefore, findings cannot be generalised to pregnant women exposed to less severe violence not requiring hospitalisation. Also, many violent events in Australia are never reported,[38] particularly among Indigenous people and particularly incidents involving domestic violence. Limited access to hospitals in rural and remote areas may also result in underreporting [39]. We also acknowledge that women in the comparison group might have been exposed to violence during pregnancy that did not require hospitalisation or was not reported, consequently underestimating the risk of adverse outcomes associated with violence. Despite this, it is known that pregnant women are more likely to seek medical attention due to concern for their unborn baby [40]. This study investigated maternal and foetal outcomes for women who were victims of an acute episode of violence during pregnancy. Exposure to chronic violence, on the other hand, may affect pregnancy outcomes differently and warrant further studies.

Finally, a large number of factors other than interpersonal violence are known to contribute to poor maternal and foetal outcomes. These include alcohol and drug usage, living conditions, health conditions, nutrition, level of prenatal care and socioeconomic status. Adverse outcomes can occur as a result of interpersonal violence, biological, behavioural and socioeconomic factors [10]. However, information on such potential confounding factors was not captured in the available databases.

\section{Conclusions}

In conclusion, pregnant women hospitalised for an incident of interpersonal violence are at significantly increased risk of adverse maternal and foetal outcomes. Since poor maternal and foetal outcomes can have long term health consequences, greater priority needs to be given to the primary prevention of violence against pregnant women and the care given to these women following an incident of violence. In developing a response to violence, the findings indicate that prevention programs should target younger pregnant women and focus on preventing intimate partner violence. It is imperative that culturally appropriate intervention programs are implemented to reduce the high rate of violence against Indigenous pregnant women and also that they receive appropriate care and monitoring after exposure to violence.

\section{Acknowledgements and Funding}

We would like to thank the Office of Research and Development at Curtin University for funding this project. We would also like to thank the Data Linkage Unit at the Department of Health, Western Australia for extraction of the data set.

\section{Author details}

${ }^{1}$ Curtin-Monash Accident Research Centre (C-MARC), School of Public Health, Curtin University, GPO Box U1987, Perth, Western Australia 6845, Australia. ${ }^{2}$ School of Public Health, Curtin University, GPO Box U1987, Perth, Western Australia 6845, Australia. ${ }^{3}$ Department of Health Care and Epidemiology, University of British Columbia, 2329 West Mall, Vancouver, British Columbia V6T 1Z4, Canada.

\section{Authors' contributions}

LBM conceived of the study, participated in its design and co-ordination, acquired the data, analysed and interpreted data and was involved in the drafting and revising of the manuscript. AHL participated in the design of the study, in data analysis and revised the manuscript critically for intellectual content. PAJ participated in the study's conception and design, interpretation of data and revised the manuscript for intellectual content. MLF contributed to the design of the study, assisted in data acquisition and the drafting of the manuscript. All authors read and approved the final manuscript.

\section{Competing interests}

The authors declare that they have no competing interests.

Received: 21 February 2011 Accepted: 12 October 2011

Published: 12 October 2011

\section{References}

1. VicHealth: The health costs of violence. Measuring the burden of disease caused by intimate partner violence. A summary of findings. Carlton South, Victoria, Victorian Health Promotion Foundation; 2004.

2. Mouzos J, Makkai T: Women's experiences of male violence: Findings from the Australian component of the International Violence Against Women Survey (IVAWS). Canberra, Australian Institute of Criminology; 2004, Report No. 56.

3. Eichenwald EC, Stark AR: Management and outcomes of very low birth weight. N Engl J Med 2008, 358:1700-1711.

4. Krug EG, Dahlberg LL, Mercy JA, Zwi AB, Lozano R: World report on violence and health. Geneva: World Health Organization; 2002.

5. World Health Organisation: International Classification of Diseases, Ninth Revision. Geneva, World Health Organisation; 1975.

6. World Health Organisation: International Classification of Diseases and Related Health Problems, Tenth Revision. Geneva, World Health Organisation; 1992.

7. Australian Bureau of Statistics [ABS]: Personal Safety Survey. Canberra, Australian Bureau of Statistics; 2006, Cat. No. 4906.0.

8. Covington $\mathrm{DL}$, Hage $\mathrm{M}$, Hall $\mathrm{T}$, Mathis $\mathrm{M}$ : Preterm delivery and the severity of violence during pregnancy. J Reprod Med 2001, 46:1031-1039.

9. Rachana C, Suraiya K, Hisham AS, Abdulaziz AM, Hai A: Prevalence and complications of physical violence during pregnancy. Eur J Obstet Gynecol Reprod Biol 2002, 103:26-29.

10. Murphy CC, Schei B, Myhr TL, Du Mont J: Abuse: a risk factor for low birth weight? A systematic review and meta-analysis. CMAJ 2001, 164:1567-1572

11. Sharps PW, Laughon K, Giangrande SK: Intimate partner violence and the childbearing year: maternal and infant health consequences. Trauma Violence Abus 2007, 8:105-116.

12. El Kady D, Gilbert WM, Xing G, Smith LH: Maternal and neonatal outcomes of assaults during pregnancy. Obstet Gynecol 2005, 105:357-363.

13. Lipsky S, Holt VL, Easterling TR, Critchlow CW: Impact of police-reported intimate partner violence during pregnancy on birth outcomes. Obstet Gynecol 2003, 102:557-564.

14. Meuleners $L B$, Hendrie D, Lee AH: Hospitalisations due to interpersonal violence: a population-based study in Western Australia. Med J Aust 2008, 188:572-575

15. National Coding Centre: The Official NCC Australian Version of ICD- 10AM Tabular List (Annotated) and Index of Procedures ICD-10-AM MBS- 
Extended. National Coding Centre, Faculty of Health Sciences, University of Sydney; 5 2006, Sydney.

16. SAS Package Version 9.1: Cary, NC: SAS Institute Inc; 2007.

17. Stewart D, Cecutte A: Physical abuse in pregnancy. CMAJ 1993, 149:1257-63.

18. Janssen PA, Holt VL, Sugg NK, Emanuel I, Critchlow CM, Henderson AD: Intimate partner violence and adverse pregnancy outcomes: a population-based study. Am J Obstet Gynecol 2003, 188:1341-1347.

19. Coker AL, Sanderson M, Dong B: Partner violence during pregnancy and risk of adverse pregnancy outcomes. Paediatr Perinat Epidemiol 2004 18:260-269.

20. Cokkinides VE, Coker AL, Sanderson M, Addy C, Bethea L: Physical violence during pregnancy: maternal complications and birth outcomes. Obstet Gynecol 1999, 93:661-666.

21. Fanslow J, Silva M, Robinson $E$, Whitehead A: Violence during pregnancy: associations with pregnancy intendedness, pregnancy-related care, and alcohol and tobacco use among a representative sample of New Zealand women. Aust N Z J Obstet Gynaecol 2008, 48:398-404.

22. Fanslow J, Silva M, Whitehead A, Robinson E: Pregnancy outcomes and intimate partner violence in New Zealand. Aust N Z J Obstet Gynaecol 2008, 48:391-397.

23. Kim $H$, Cain $R$, Viner-Brown $S$ : Intimate partner violence before or during pregnancy in Rhode Island. Med Health R I 2010, 93:29-31.

24. Neggers Y, Goldenberg R, Cliver S, Hauth J: Effects of domestic violence on preterm birth and low birth weight. Acta Obstet Gynecol Scand 2004, 83:455-460.

25. Silverman JG, Decker MR, Reed E, Raj A: Intimate partner violence victimization prior to and during pregnancy among women residing in 26 U.S. states: associations with maternal and neonatal health. Am J Obstet Gynecol 2006, 195:140-148.

26. Valladares E, Ellsberg M, Pena R, Hogberg U, Persson LA: Physical partner abuse during pregnancy: a risk factor for low birth weight in Nicaragua. Obstet Gynecol 2002, 100:700-705.

27. Yang MS, Ho SY, Chou FH, Chang SJ, Ko YC: Physical abuse during pregnancy and risk of low-birthweight infants among aborigines in Taiwan. Public Health 2006, 120:557-562.

28. Li Q, Kirby RS, Sigler RT, Hwang SS, Lagory ME, Goldenberg RL: A multilevel analysis of individual, household, and neighborhood correlates of intimate partner violence among low-income pregnant women in Jefferson county, Alabama. Am J Public Health 2010, 100:531-539.

29. Lipsky S, Holt VL, Easterling TR, Critchlow CW: Police-reported intimate partner violence during pregnancy: who is at risk? Violence Vict 2005, 20:69-86.

30. Moraes $\mathrm{CL}$, Reichenheim ME: Domestic violence during pregnancy in Rio de Janeiro, Brazil. Int J Gynaecol Obstet 2002, 79:269-277.

31. Bohn DK, Tebben JG, Campbell JC: Influences of income, education, age, and ethnicity on physical abuse before and during pregnancy. J Obstet Gynecol Neonatal Nurs 2004, 33:561-571.

32. Gazmararian JA, Lazorick S, Spitz AM, Ballard TJ, Saltzman LE, Marks JS: Prevalence of violence against pregnant women. JAMA 1996, 275:1915-1920.

33. Hunter E, Milroy H: Aboriginal and Torres Strait Islander suicide in context. Arch Suicide Res 2006, 10:141-57.

34. Memmott $P$, Stacy $R$, Chambers $C$, Keys $C$ : Violence in Indigenous Communities: Full Report. Canberra, Crime Prevention Branch, Attorney General's Department; 2001.

35. McGwin G, Sims RV, Vonne Pulley L, Roseman JM: Relations among chronic medical conditions, medications, and automobile crashes in the elderly: a population-based case-control study. Am J Epidemiol 2000, 152:5.

36. Holland CA, Handley S, Fleetam C: Older drivers, illness and medication. London, Department for Transport; 2003.

37. Clark A, Preen DB, Ng JQ, Semmens JB, Holman CDJ: Is Western Australia representative of other Austrlalian States and Territories in terms of key socio-demographic and health economic indicators? Aus Health Rev 2010, 34:210-215.

38. Wallace C, Burns L, Gilmour S, Hutchinson D: Substance use, psychological distress and violence among pregnant and breastfeeding Australian women. Aust N Z J Public Health 2007, 31:51-56.
39. Gillam C, Legge M, Stevenson M, Gavin A: Injury in Western Australia: an epidemiology of injury 1989 to 2000. Perth, Department of Health Western Australia; 2003.

40. Weiss HB, Sauber-Schatz EK, Cook L: The epidemiology of pregnancyassociated emergency department injury visits and their impact on birth outcomes. Accid Anal Prev 2008, 40:1088-1095.

\section{Pre-publication history}

The pre-publication history for this paper can be accessed here: http://www.biomedcentral.com/1471-2393/11/70/prepub

doi:10.1186/1471-2393-11-70

Cite this article as: Meuleners et al: Maternal and foetal outcomes among pregnant women hospitalised due to interpersonal violence: $\mathrm{A}$ population based study in Western Australia, 2002-2008. BMC Pregnancy and Childbirth 2011 11:70.

\section{Submit your next manuscript to BioMed Central and take full advantage of:}

- Convenient online submission

- Thorough peer review

- No space constraints or color figure charges

- Immediate publication on acceptance

- Inclusion in PubMed, CAS, Scopus and Google Scholar

- Research which is freely available for redistribution

Submit your manuscript at www.biomedcentral.com/submit
Biomed Central 